\title{
Crisis de la educación superior chilena
}

\author{
CECILIA SEPÚLVEDA C. ${ }^{1}$ \\ 1. Decana Facultad de Medicina, Universidad de Chile.
}

Sin duda la educación superior en Chile enfrenta una crisis estructural y sus causas son múltiples. Las movilizaciones estudiantiles que hoy presenciamos son sólo una expresión más de esta larga crisis.

Para entenderla y buscar soluciones, se requiere identificar del modo más objetivo posible, cuál es la esencia de este malestar, el que no es nuevo y que hoy se manifiesta en diferentes sectores de la comunidad universitaria: estudiantes y académicos, incluso de universidades privadas.

En este contexto uno de los problemas más graves, es la situación por la que atraviesa la educación superior estatal o pública, la que podemos caracterizar como de incertidumbre frente al futuro.

Por muchos años las Universidades estatales o públicas, jugaron un rol predominante en nuestra sociedad tanto en la formación de profesionales y técnicos, en el desarrollo de investigación de alto nivel, en la construcción de una cultura e identidad nacional, como asímismo, hicieron un aporte central por más de un siglo al desarrollo económico y social del país.

También es necesario señalar, que los estudiantes universitarios antes de la década de los 80 , formaban parte de una élite y una parte importante provenía de la enseñanza pública, lo que permitía contar con personas de una gran diversidad económico-social que enriquecía la convivencia y la formación universitaria.

Posteriormente, durante los años 80 y con mayor fuerza durante los 90, esta situación cambió por distintas razones. Primero, porque durante el régimen militar se aplicó una política de shock de la economía, como forma de hacer frente a la crisis económica que enfrentaba el país, al igual que otros de América Latina, instaurándose un modelo neoliberal. Ello significó que se redujera rápidamente el presupuesto estatal a las Universidades estatales, generando así un grave y rápido deterioro del desarrollo académico y se impuso una política de autofinanciamiento, que en el caso de la Universidad de Chile, hoy significa financiar sobre el $90 \%$ de sus actividades.

Segundo, a partir de una mayor demanda por educación superior, el régimen creó las condiciones políticas y legales para que surgieran las Universidades privadas, lo que por razones obvias, les permitió y facilitó competir en condiciones favorables y más competitivas con las universidades públicas.

Tercero, las Universidades estatales a partir de entonces, debieron “jugar y juegan”, aún en una cancha muy dispareja, ya que por su naturaleza "pública” están sujetas a numerosas trabas, lo que burocratiza su gestión, están sometidas a severas restricciones en la inversión y además están impedidas de endeudarse a largo plazo (de manera excepcional este año podrán hacerlo). En definitiva todas dificultades que no ayudan a realizar una gestión moderna, profesional y eficiente. Sin embargo a pesar de ello, las universidades estatales son quienes lideran los rankings nacionales y ocupan lugares importantes a nivel internacional, tanto en calidad como en producción científica.

Por otra parte, los requerimientos que existen actualmente en el país respecto a la formación de profesionales y técnicos es alta. El actual nivel de desarrollo económico, social y cultural del país necesita más y mejores profe-

Correspondencia a:

Cecilia Sepúlveda C.

csepulveda@med.uchile.cl 
sionales.

Existen en la actualidad cerca de 1 millón de estudiantes universitarios y se señala que en los próximos años este número alcanzaría a un 1 millón 400 mil. Aquí vale hacerse la siguiente pregunta: ¿basta sólo con preocuparse por la cantidad de estudiantes en formación o también es necesario preocuparse por la calidad de dicha formación? La respuesta parece obvia. Por ello es que es urgente y necesario articular todos los mecanismos políticos, legales y éticos, que permitan que los centros de formación de educación superior cuenten con las competencias requeridas y se encuentran acreditadas por una instancia independiente y transparente que les autorice a cumplir con la misión de educar. Este es un tema crucial, si no se aborda estaremos avalando lo que los economistas llaman la distorsión “del mercado", pero sobre todo, estaremos avalando que muchos de estos centros estén orientados sólo al lucro.

De lo que se trata es de cómo transparentamos el funcionamiento de la educación superior, como emparejamos la cancha para que las Universidades estatales que tanto aporte han hecho al país, tengan un trato equitativo y justo, como así mismo se les entregue el presupuesto que requieren por parte del Estado.

La movilización que los estudiantes universitarios y secundarios iniciaron en mayo de 2011 por un acceso equitativo y de calidad a la educación, en particular por asegurar que la educación superior no dependa de los ingresos de las familias, demostró cuánto ha madurado en la sociedad chilena la conciencia de que la equidad educativa es un factor determinante de la movilidad social, pero sobre todo un malestar por las inequidades existentes.

El factor central determinante fue el alto endeudamiento de muchas familias de los quintiles más bajos y medios para financiar los estudios de sus hijos, tanto en universidades estatales como privadas, y originado por las altas tasas de interés cobradas por los bancos para financiar el Crédito con Aval del Estado, ya que el costo de los estudios excedía las posibilidades de pago de muchas familias.

El debate hasta ahora ha puesto el acento en el financiamiento, por cierto un asunto central, puesto que se relaciona con la perspectiva de que el Estado se comprometa en un esfuerzo sostenible por fortalecer la educación pública. Sin embargo, no puede perderse de vista que en Chile ha habido y seguirá habiendo un sistema de educación mixta de educación, y que la segunda también debe tener la atención del Estado en orden a fiscalizar más rigurosamente a los colegios y universidades no estatales que reciben fondos del Estado.

Por ello en una perspectiva de largo plazo, los cambios en educación exigen implementar una estrategia destinada a asegurar niveles de calidad compatibles con el deseo que el país avance hacia el desarrollo y donde el Estado tiene la responsabilidad de velar porque así sea.

Casi nadie se opone a realizar cambios profundos en la educación. La opinión pública mayoritariamente apoyó las demandas de los estudiantes, no así las formas que en ocasiones adoptaron las protestas, pero debemos decir que los profundos cambios que se requieren suelen demorar más de lo que nos gustaría.

En definitiva, 2011 fue un año complejo para la educación. A pesar de las movilizaciones realizadas, muchos de los temas planteados seguirán pendientes y lo más probable es que el año 2012 se retomen y continúen las manifestaciones, esperemos que estas conduzcan al encuentro de soluciones de fondo, lo que seguramente requerirá un esfuerzo y trabajo sostenido de la Sociedad en su conjunto. 